Full length article

\title{
Infants' sensitivity to rhyme in songs
}

\author{
Laura E. Hahn ${ }^{\mathrm{a}, \mathrm{b}, *}$, Titia Benders ${ }^{\mathrm{c}, \mathrm{d}}$, Tineke M. Snijders ${ }^{\mathrm{e}, \mathrm{f}}$, Paula Fikkert ${ }^{\mathrm{a}}$ \\ a Centre for Language Studies, Radboud University, Nijmegen, The Netherlands \\ ${ }^{\mathrm{b}}$ International Max Planck Research School for Language Sciences, Nijmegen, The Netherlands \\ ${ }^{\mathrm{c}}$ Department of Linguistics, Macquarie University, North Ryde, Australia \\ ${ }^{\mathrm{d}}$ ARC Centre of Excellence in Cognition and its Disorders, Australia \\ ${ }^{\mathrm{e}}$ Max Planck Institute for Psycholinguistics, Nijmegen, The Netherlands \\ ${ }^{\mathrm{f}}$ Donders Institute for Brain, Cognition and Behaviour, Centre for Cognitive Neuroimaging, Radboud University, Nijmegen, The Netherlands
}

\section{A R T I C L E I N F O}

\section{Keywords:}

Infant-directed song

Rhyme

Spontaneous processing

\begin{abstract}
A B S T R A C T
Children's songs often contain rhyming words at phrase endings. In this study, we investigated whether infants can already recognize this phonological pattern in songs. Earlier studies using lists of spoken words were equivocal on infants' spontaneous processing of rhymes (Hayes et al., 2000; Jusczyk et al., 1999). Songs, however, constitute an ecologically valid rhyming stimulus, which could allow for spontaneous processing of this phonological pattern in infants. Novel children's songs with rhyming and non-rhyming lyrics using pseudo-words were presented to 35 9-month-old Dutch infants using the Headturn Preference Procedure. Infants on average listened longer to the non-rhyming songs, with around half of the infants however exhibiting a preference for the rhyming songs. These results highlight that infants have the processing abilities to benefit from their natural rhyming input for the development of their phonological abilities.
\end{abstract}

\section{Introduction}

Infants' daily routines are often accompanied by songs and nursery rhymes. Caregivers recite nursery rhymes during playtime and sing lullabies to soothe their child or to entertain him/her, e.g. while driving or during a diaper change (Trehub et al., 1997). Songs and nursery rhymes clearly serve a social-emotional function. The body of research on phonological processing of rhymes in toddlers and kindergartners is quite extensive, but only rarely makes use of ecologically valid stimuli such as songs and nursery rhymes. The central question in this study is whether 9-month-old infants exploit songs and rhymes to spontaneously process phonological patterns of their native language.

A very frequent phonological phenomenon in songs and nursery rhymes is the occurrence of rhymes at phrase endings. A phrasefinal rhyme is a sound pattern that is repeated at the end of verses or phrases (Fabb, 1999). In Western children's songs, rhymes typically include the last stressed syllable and, if applicable, the following unstressed syllables. The unit of repetition in phrase-final rhymes typically is a whole word, excluding the word-onset (e.g. Stallworthy, 1996).

Previous research investigating the effect of rhyme on linguistic processing in children mostly focused on kindergartners and has shown clear benefits of rhymes in word learning and phonological processing tasks. For example, 2- to 4-year-olds benefit from rhyming stories when learning new words, as they are better able to learn a novel word if it rhymes with the phrase-final word of the previous verse (Read, 2014). Children in the same age range also benefit from listening to rhyming stories, as opposed to prose stories, before completing a rhyme/alliteration detection task (D. S. Hayes, 2001). These effects might be attributed to the increased

\footnotetext{
* Corresponding author at: Radboud University Nijmegen, Postbus 9103, 6500 HD Nijmegen, The Netherlands.

E-mail address: 1.hahn@let.ru.nl (L.E. Hahn).
} 
predictability of the phonological content of a rhyming story (Cook, 1997; Rubin, 1995). This higher predictability of phonological content might in turn increase phonological sensitivity, as is evident from the results of the rhyme/alliteration detection task (Hayes, 2001). Similar conclusions can be drawn from a study with 6-year-olds (Sheingold \& Foundas, 1978). After having listened to a story in rhyme or prose, children were asked to recall details of the story. Children were equally successful in that task, regardless of whether they had heard a rhyming or non-rhyming story. However, the children were more successful in sorting the events of rhyming stories into ordered sequences than those of non-rhyming stories. The authors hypothesized that the rhyming verse couplets were helpful to reconstruct the order of content appearing in the story, due to the predictability of the phonological form of rhyming words. Thus, toddlers and preschoolers already make use of rhymes to predict upcoming linguistic input and to memorize the content of a story.

A crucial component of rhyme sensitivity is the ability to recognize that rhyming words are different from repetitions of identical words: children have to be able to recognize that e.g. /bear/ and /pear/ share phonological material, but differ in their onset consonants. This is an important ability, as it has been suggested that the awareness of such subtle phonological differences has important implications for later literacy development (De Cara \& Goswami, 2002; Goswami et al., 2002). Infants as young as 11 and 18 months of age are already sensitive to small changes to onset consonants (2009, Swingley, 2005). Additionally, 2-year-old children are able to identify the target in a set of rhyming items as soon as they hear the non-overlapping onset consonant (Swingley, Pinto, \& Fernald, 1999). Upon acquisition of novel words, 14-month-olds are able to recognize subtle phonological differences between highly similar items, such as /din/ and /bin/ (Yoshida, Fennell, Swingley, \& Werker, 2009). Moreover, infants as young as 16 months are even able to group such rhyming words apart from another set of words that also overlaps in phonological material but do not rhyme (e.g. /dib/ and /gib/ vs. /deb/) (Floccia, Nazzi, Delle Luche, Poltrock, \& Goslin, 2014). At the start of their second year of life infants thus already possess impressive phonological processing abilities that allow them to differentiate between and acquire rhyming single words.

However, there is only sparse evidence for rhyme processing in infants younger than one year of age and none of the studies in question used ecologically valid stimuli that nursery rhymes or songs provide. In one study that used a variant of the Headturn Preference Procedure (Kemler Nelson, Jusczyk, \& Mandel, 1995), 9-month-old American-English infants did not show a higher sensitivity for CVC word lists that rhymed as compared to CVC word lists that did not (e.g. bad, pad, lad (shared -VC) vs. vip, zut, mog (no phonological overlap), Jusczyk, Goodman, \& Baumann, 1999, experiment 1). However, infants in the same study and using the same procedure were sensitive to the mirror image of rhymes, that is phonological overlap at the beginning of the syllable (shared CV-, experiment 2) and overlapping syllable onsets (shared C-, experiment 3). Another study did find sensitivity to rhyming versus non-rhyming single words in 2-year-old English toddlers, but did not find evidence for this ability in 8.5-month-old infants (Braze, McRoberts, \& Mc Donough, 2011). Within this study, both toddlers and infants were tested using the same visual fixation paradigm. While the toddlers looked significantly longer when hearing rhyming versus non-rhyming words, no significant looking time differences were found for infants tested on the same set of words. Infants thus recognize repetition of intra-syllabic units at word onsets in lists of single words, but do not spontaneously display such recognition for rhyming single words.

As a counterpoint to the absence of a spontaneous discrimination between rhyming and non-rhyming stimuli reported in the work by Jusczyk et al. (1999) and Braze et al. (2011), two other studies with 7-to-13-month-old English infants found that they were able to detect changes from one rhyme pattern to another under specific circumstances (Hayes, Slater, \& Brown, 2000; Hayes, Slater, \& Longmore, 2009). These infants were able to detect a change from one rhyme (e.g., bad, dad, fad) to another (beg, deg, feg) in a Conditioned Headturn Preference Procedure (Werker, Polka, \& Pegg, 1997), suggesting that they are sensitive to the shared rhymes between words. Crucially, infants in both studies by Hayes and colleagues were trained to respond to a change in rhyme rather than showing a spontaneous reaction as assessed in an unconditioned Headturn Preference Procedure. Moreover, due to the elaborate training required for this paradigm, only a subset of the tested infants actually contributed analyzable trials. This gives rise to the possibility that the early rhyme sensitivity observed in this study only holds for rather mature infants that might differ substantially from a set of average infants. The study nevertheless provides a first indication infants can potentially process rhymes at an early age under certain circumstances.

Taken together, the evidence so far suggests that infants do not have a spontaneous preference for rhyming or non-rhyming word lists (Jusczyk et al., 1999), indicating that they are not able to differentiate between rhyme and non-rhyme. However, they can be trained to react to a change in rhyme in lists of words (Hayes et al., 2000, 2009). Although a specific sensitivity to rhymes is clearly present early in life, these results do not shed light on the question whether infants can and do spontaneously use this sensitivity when they encounter rhymes in their daily lives.

A context that may facilitate infants' spontaneous (instead of trained) processing of rhymes is song. Songs contain rhymes within a solid scaffold of melody and rhythm, which caregivers express through various multi-modal cues (Bergeson \& Trehub, 2002; Delavenne, Gratier, \& Devouche, 2013; Falk \& Kello, 2017; Longhi, 2009; Nakata \& Trehub, 2011). These structural cues potentially enable infants to attend longer to infant-directed song compared to infant-directed speech (e.g. Costa-Giomi, 2014). In fact, research has repeatedly identified infant-directed singing as a tool for infant arousal regulation (e.g. Trehub \& Nakata, 2002). Prolonged attention to song might subsequently enable infants to extract information from song that is otherwise inaccessible to them. Yet, there are very few studies exploring infants' linguistic processing abilities in song, and none focused on the processing of rhyme. Two studies showed that infants can detect a change in the order of a string of syllables only when the syllable string is sung on a melody, but not when the string is spoken (Lebedeva \& Kuhl, 2010; Thiessen \& Saffran, 2009). Both studies used the Headturn Preference Procedure, with infants from 6 to 8 months old (Thiessen \& Saffran, 2009) and 11 months old (Lebedeva \& Kuhl, 2010). These studies provide evidence that infants actively encode the phonological content of songs, an important prerequisite to detect rhymes at phrase endings in songs. 
That the scaffold of melody and rhyme has potential benefits for language learning has recently been shown in adult learners (Bebout \& Belke, 2017). In this study, adults acquired the gender system of an artificial language by listening to sentences describing action sequences. Learners exposed to sentences with both rhymes and melody outperformed the learners exposed to spoken prose, only-rhyming or only-sung sentences. These results show that rhyme and melody in a song can form the optimal stimulus for language learning. Perhaps infants are already able to benefit from these structural features in rhyming songs for the acquisition of their first language. For this, however, it is necessary that infants spontaneously process rhymes at phrase endings in songs. Presumably, detecting a rhyme at phrase ends requires more segmentation and working memory skills than detecting rhymes in single words. On the other hand, the rhyming phrases and not the single words are in accordance with the vast amount of rhyming input infants get. In the current study we move from rather artificial single word stimuli to a stimulus that is familiar to infants. In this way we will shed light on infants' processing abilities of natural infant-directed singing, as opposed to simple single words.

Spontaneous rhyme processing could also be fostered by the phrase-final position at which rhymes typically occur within Western children's songs. In speech, phrase boundaries have been associated with enhanced phonological processing in infants (Johnson, Seidl, \& Tyler, 2014). For songs, there is recent evidence that already at 6 months of age, infants are sensitive to the phrase boundaries in song melodies (Hahn et al., in prep). Consequently, the current study investigates spontaneous processing of rhymes embedded at phrase-endings.

In the current study, we used the Headturn Preference Procedure to investigate whether infants spontaneously process rhymes that are presented at phrase boundaries in songs, an ecologically valid rhyme context that potentially facilitates rhyme processing, without explicit training. With this design we aim to lay the ground for future research that can explore the possibility that rhyming songs are a source of linguistic learning for infants. So far, songs and nursery rhymes have only very rarely been studied as a potential vehicle for language learning in infancy and no study yet has focused on rhyme. To be comparable with previous studies (Braze et al., 2011; Hayes et al., 2000; Jusczyk et al., 1999), we tested 9-month-old Dutch infants. However, novel children's songs were used as stimuli, as opposed to the lists of single words used in previous studies. Due to this difference in stimuli, no concrete prediction in terms of the preference direction of infants could be made. However, given the ubiquity of phrase-final rhymes in song and nursery rhymes (Burling, 1966; Rubin, 1995), a familiarity preference for rhyming songs seemed more likely. Crucially, a preference in either direction would indicate infants' spontaneous processing of rhymes in songs.

\section{Method}

\subsection{Participants}

The final sample of participants consisted of 35 infants (21 female, $M_{\text {age }}$ in days $=292$; range 275-304). Twelve more infants were tested but excluded because they cried during the experiment $(n=3)$, because they clapped or danced while listening to the songs and were therefore unable to perform the head-turn procedure $(n=6)$, because they only contributed trials for one experimental condition $(n=1)$, or because the parent terminated the session $(n=2)$.

A statistical power analysis using $G^{*}$ Power was conducted to obtain an estimation of the required sample size (Faul, Erdfelder, Lang, \& Buchner, 2007). The design and procedure of the current study were comparable to the study by Jusczyk et al. (1999). Their experiment 2 on sensitivity to repeating word-onset clusters was used as a reference for the power analysis, as their experiment 1 , on rhyme sensitivity, did not render a statistically significant effect. Based on the means and standard deviations reported for Experiment 2 and a conservatively estimated correlation between groups of 0.2 , we calculated Cohen's $d_{\text {Experiment } 2}=0.506$. The power analysis based on this estimated effect size revealed a minimum required sample size of 33 participants to reach $80 \%$ power in a two-sided $t$ test with alpha $=0.05$. Consequently, we aimed at a final sample of at least 33 infants, and tested 47 infants, anticipating $30 \%$ dropout.

All participating infants were reported by the parents to be born full-term, have normal hearing, no familial risk of language or reading problems and come from a monolingual Dutch household. Parents of one child reported that the child is exposed to Berber during occasional family visits on weekends (about six hours per month). On a questionnaire administered before the experiment, the visiting caregivers indicated the amount of exposure to different musical sources for their infant (see page 4 of the supplementary material for an English translation of this questionnaire). The majority of caregivers indicated that their child listens to songs sung live by one of the infants' caregivers on a daily basis ( $90 \%$, singers are mostly mothers). All children but one were exposed to songs from birth onwards (one child from the age of 4 months). These data were not used for analysis of individual differences, as the frequency of song and rhyme exposure was highly similar across children (93\% of participating infants are exposed to Dutch children's songs on a daily basis). All parents were given the choice between a children's book and $10 €$ as compensation for their participation. The parents gave informed consent prior to participating. Testing adhered to APA ethical standards and was conducted in the Baby and Child Research Center at Radboud University Nijmegen, The Netherlands.

\subsection{Materials}

The stimuli were a set of children's songs, consisting of novel melodies with accompanying novel lyrics. Each song occurred in a rhyming and non-rhyming version. These versions only differed in the phrase-final syllable and were otherwise identical.

\subsubsection{Melodies}

Novel melodies were created to exclude song familiarity as a potential factor influencing the results. All melodies comprised two 

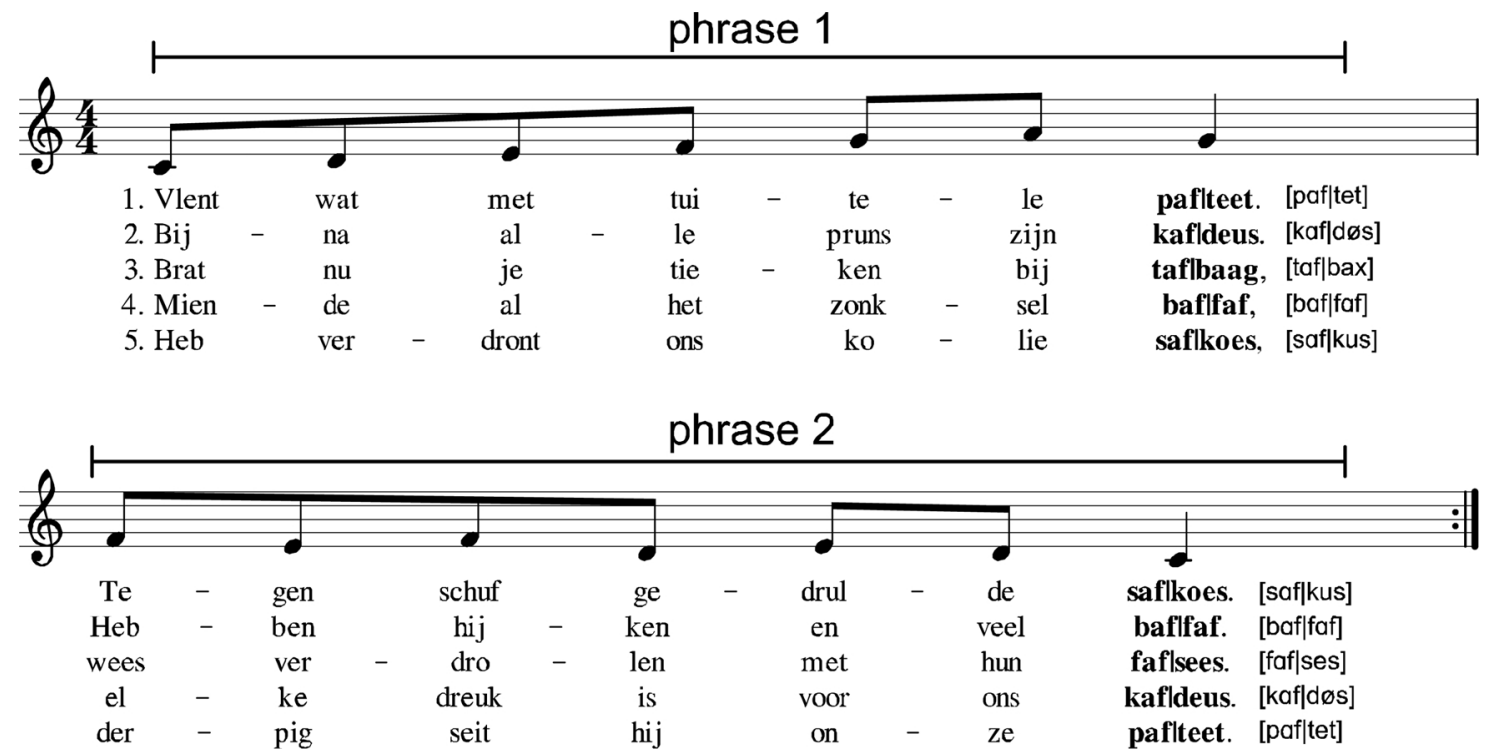

Fig. 1. Example Stimulus. Lyrics in Nonsense-Dutch, Phrase-final words in bold and International Phonetic Alphabet (IPA) transcription (International Phonetic Association, 1999); Numbers 1-5 = Verse 1-5.

melodic phrases that had a median length of seven tones each (range 6-9 tones). Melodies were set in a major key and consisted of intervals up to a quint. To mimic the two-phrase structure of many Germanic folk songs (Shanahan \& Huron, 2011), the second melodic phrase was constructed to sound closed by using a falling melodic contour that ended on the tonic. Melodies were notated using the software MuseScore (musescore.org). An example melody can be seen in Fig. 1. The sound files of the stimuli can be found under this link: https://osf.io/gnadw/?view_only=fc4ee7caa798455cbda463448061206f, the lyrics can be found in the Supplementary material.

\subsubsection{Lyrics}

For every melody, a rhyming and a non-rhyming version of the lyrics was created, which only differed in the phrase-final pseudowords: monosyllabic CVC combinations of voiceless obstruents [p, t, k, f, s, x] and vowels [i, e, o, ə, a, a, u, عi, ø]. In the rhyming version, the phrase-final words of the phrases all rhymed, whereas in the non-rhyming version they did not rhyme (see again Fig. 1 , and see supplementary materials for the full set of lyrics).

The lyrics were written using Dutch function words and auxiliaries, and phonotactically legal pseudo-words for content words. These Nonsense-Dutch words were used to avoid any word familiarity effects. For every two-phrase melody, five two-phrase verses were written (1 to 5 in Fig. 1), rendering a 10-phrase song. Each phrase ended with a slot for a monosyllabic phrase-final word. These slots were filled with rhyming pseudo words for the rhyming version (e.g., [paf, saf, faf, kaf]) and filled with non-rhyming pseudo words for the non-rhyming version (e.g., [tet, kus, døs, bax]). Some phrase-final words were used twice within the same song and version (e.g. [kaf] and [døs] in Fig. 1), due to the relatively small number of rhyming mono-syllabic Dutch pseudo-words. If a pseudoword had to be repeated within the rhyming version of a song, it was placed as far away as possible from the first occurrence of the word. The corresponding phrase-final word in the non-rhyming version was also repeated at the same position. The text setting of the songs was judged to be appropriate by two Dutch native speakers.

\subsubsection{Songs}

2.2.3.1. Recording procedure. A female Dutch singer, with more than ten years of singing experience in choirs and solo-lessons, was recorded singing the songs. She was instructed to sing in a friendly, infant-directed manner. A visual metronome was displayed to the singer, set at 61 beats per minute. This tempo was found to be the most convenient tempo for the singer and enabled her to sing both versions of a song at nearly equal tempo. The singer used a tuning fork to start the rhyming and non-rhyming song versions from the same tone. The songs were recorded in a sound-proof recording studio using Adobe Audition and were exported as. wav files with a sampling rate of $44.1 \mathrm{kHz}$ and a resolution of 16 bits.

2.2.3.2. Acoustic manipulations. Noise and disturbing sounds were deleted from the recording with Audacity (version: 2.0.5). All other acoustic manipulations were performed using Praat (Boersma \& Weenink, 2014). All songs were set to $65 \mathrm{~dB}$ intensity, which was the median intensity of the original songs. The authors of the study found the original recording of the songs to be rather slow for typical children's songs. Therefore, the tempo was increased by shortening the songs' duration by $10 \%$, using a duration tier and resynthesis with overlap-add in Praat. A $500 \mathrm{~ms}$ period of silence was inserted between phrases of a song, to ensure that gaps between phrases were of equal duration across the rhyming and non-rhyming versions of each song. All songs faded out at $26 \mathrm{~s}$ using a twosecond fade-out resulting in songs of $28 \mathrm{~s}$ long (median of 8 phrases per song version, range: 8 to 9 phrases). 
Table 1

Acoustic characteristics of the experimental stimuli with means and standard deviations in parenthesis. All pitch analyses were done using Praat's standard interpolation method using a pitch range of $75-1200 \mathrm{~Hz}$, to accommodate the relatively high pitch in singing.

\begin{tabular}{llll}
\hline & & Rhyming & Non-rhyming \\
\hline Duration (ms) & Phrases & $2732(274)$ & $2728(255)$ \\
Fundamental frequency (Hz) & Phrase-final word & $648(99)$ & $626(92)$ \\
& Phrases & $326(34)$ & $327(35)$ \\
Intensity (dB) & Phrase-final word & $293(63)$ & $291(64)$ \\
& Phrases & $65(2)$ & $64(2)$ \\
& Phrase-final word & $53(7)$ & $55(7)$ \\
\hline
\end{tabular}

2.2.3.3. Selection of the final song sample. Nine songs were selected from the full set of songs. These nine songs were considered to sound most natural, judged by the authors of the study. Furthermore, their text could easily be transcribed by two Dutch native speakers, indicating that the Nonsense-Dutch lyrics conform to real Dutch phonology. Duration, fundamental frequency and intensity of the songs' phrases and phrase-final words are summarized in Table 1. A by-stimulus repeated measures ANOVA confirmed that no significant differences were present between the rhyming and non-rhyming versions of a song in terms of duration, pitch and intensity (see the Supplementary materials for more details on this analysis).

\subsection{Procedure}

The experiment was run using the Headturn Preference Procedure. Three lights were placed within a three-sided booth at infant eye-level: a blue light in the center and red lights on the right and left walls of the booth. A camera was hidden below the center light to observe infant behavior from outside. Stimuli were presented via loudspeakers below the red lights. The infant and caregiver were seated in the middle of the booth, directly opposite the blue center light, exactly in between the left and right red lights.

Stimulus presentation was controlled from outside the test booth by the experimenter, using the stimulus presentation software Look! (Meints \& Woodford, 2008). The experimenter was blind to trial number and trial condition. The experimenter coded the looking behavior of the infant (left, right, center) using assigned keys. The same procedure was used for both practice trials and test trials. The whole session was recorded on video for later reliability coding (see section "reliability coding" below).

Before the experiment started, parents were briefed about the experimental procedure by the experimenter and filled out the questionnaire about their singing habits (see the supplementary material for an English translation of the questionnaire). Parents informed the experimenter about the current health status of the child (e.g. whether the child had a cold at the day of testing or had pain from teething). Recording this information is standard practice in our lab and serves possible post hoc exclusion of children. However, this did not prove to be necessary within the sample of infants in the current study. At the start of the experiment, infants were seated in the test booth on their caregiver's lap. Both caregiver and experimenter wore headphones throughout the experiment, listening to masking music (samba music played simultaneously with spoken text from various female speakers). Each trial started with the blue light in the center blinking. Once the infant fixated this light, the blue light stopped blinking and either the left or right red light began to blink. The sound stimulus started as soon as the infant turned her head to the blinking light for one second. The stimulus was continuously played until the infant turned her head away from the light for more than two consecutive seconds or until the maximum stimulus duration of $28 \mathrm{~s}$ was reached. The full testing session lasted about five minutes. Test sessions were aborted earlier if the infant fussed or if the parent indicated to stop the session. After the experiment, parents were debriefed about the research question of the experiment.

The experiment was divided in a training and test phase. During training infants could become acquainted with the lights in the testing booth and the head-turn contingent start and continuation of the stimulus presentation. For the training phase, two songs that were not used during the test phase were played. Both the rhyming and non-rhyming versions of these two songs were used for training, counterbalanced between infants for condition (rhyming / non-rhyming), order (first/second training trial) and presentation side (left/right). After these two training trials, fourteen test trials immediately followed, divided into two blocks of seven songs each. The rhyming and non-rhyming versions of each song appeared in different blocks. Infants thus never heard the same melodies within one block. The order of training songs and test songs was pseudo-randomized using Mix (Casteren, van, \& Davis, 2006), ensuring that the same side of presentation (left / right) and condition (rhyming / non-rhyming) appeared maximally three times in a row.

\subsection{Analysis}

\subsubsection{Reliability coding}

Videos of ten infants were coded offline by a second trained coder. These offline codings were compared to the online codings from the experiment by computing Pearson correlations for individual participants' online and offline total looking time per trial (Swingley, 2005). The mean correlation coefficient was 0.99 (range 0.94-0.99, SD =0.01). These high correlations warranted usage of the online codings for analysis. See the Supplementary materials for more detail on the reliability coding.

\subsubsection{Data preprocessing}

All analyses and data preprocessing have been conducted using R for Windows (R Development Core Team, 2012). Looking times 
were measured starting from the end of the second phrase of a song, when the infant could first know whether the song contained rhymes or not (mean of $6.17 \mathrm{~s}$ into the stimulus, range: $5.35-7.03 \mathrm{~s}$ ). Look durations before the second phrase ending were disregarded (see e.g. Delle Luche, Durrant, Floccia, \& Plunkett, 2014, who also disregarded looking times before a critical moment in the stimulus was reached). As a control analysis looks that ended before the end of the second phrase were compared. For these (disregarded) looks there was no significant difference in looking times between rhyming and non-rhyming songs $\left(M_{\text {non-rhyming }}=4.41 \mathrm{~s}\right.$, $S D_{\text {non-rhyming }}=0.69, M_{\text {rhyming }}=4.39 \mathrm{~s}, S D_{\text {rhyming }}=0.73,490$ trials from 35 infants, $\mathrm{p}=0.8$ ). During $56 \%$ of the trials infants looked longer than the end of the second phrase (275 trials from 35 infants). Infants contributed a median of four trials for each condition (range 1-7 in both conditions).

\subsubsection{Analysis plan}

Two analysis approaches were pursued: linear mixed effect models and paired t-tests.

2.4.3.1. Linear mixed-effect modeling. As opposed to the more traditionally used $t$-tests or ANOVAs, linear mixed effect models do not require aggregation across trials and include all individual trials of the infants (Quené \& van den Bergh, 2004).

The linear mixed effect model was fit onto Box-Cox transformed looking times (lambda $=0.32$ ), because the residuals of the same model with untransformed data were not normally distributed, as assessed through visual inspection (see also Csibra, Hernik, Mascaro, Tatone, \& Lengyel, 2016 for recommendations on why to log-transform infant looking time data). The fixed factors of the model were 1) condition (rhyme, non-rhyme), coded as orthogonal contrasts; 2) test trial number (1-14), coded as a linear polynomial; and 3) the interaction of condition and test trial number. The model included random intercepts for subjects ( $\mathrm{N}=35$ ) and songs (only the ones used during the test phase of the experiment, $\mathrm{N}=7$ ) and by-subject and by-song random slopes for the effect of condition. The R-package "lmerTest" was used to run the model and evaluate significance of the effects (Kuznetsova, Brockhoff, \& Christensen, 2016).

2.4.3.2. $t$-tests. Paired $t$-tests on the looking time data were run in addition to the linear mixed-effect model to facilitate comparison to previous literature. Looking times per condition were averaged for each participant. These averaged looking times were not transformed, again to stay in accordance with previous literature and since a Shapiro-Wilk test and a Levene's test was not significant.

2.4.3.3. Effect sizes. Cohen's $\mathrm{d}_{z}$, and Hedge's $\mathrm{g}_{a v}$ were calculated for the $t$-test dataset, according to recommendations given by Lakens (2013) and formulas introduced by Cohen (1988) and Hedges and Olkin (1985). A spreadsheet by Lakens (2013), available under https://osf.io/ixGcd/ was used for the calculation.

\section{Results}

Infants on average listened longer to the non-rhyming songs (see Fig. 2). The linear mixed-effect model (see Table 2) however

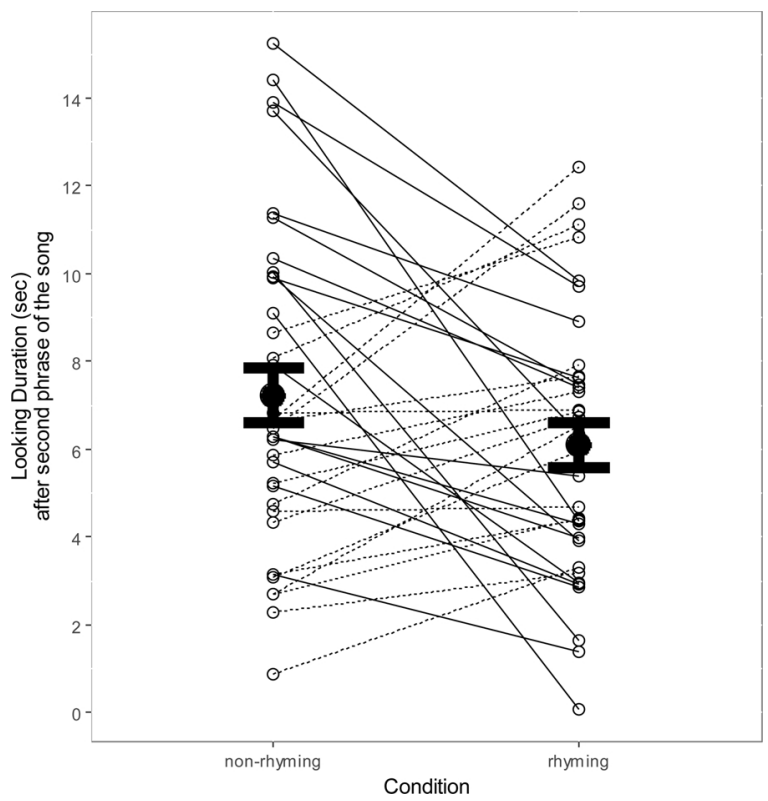

Fig. 2. Means and $95 \%$ confidence intervals for averaged looking times to rhyming and non-rhyming songs. White dots denote average looking times of individual infants for each condition. Dotted lines indicate infants with a preference for rhyming, continuous lines for infants with a preference for non-rhyming songs. 
Table 2

Parameters of the linear mixed-effect model. Based on looking times after the second phrase of every song.

\begin{tabular}{|c|c|c|c|c|c|}
\hline Predictor & Contrast Coding & $\beta$ & $S E$ & $t(z)$ & $p$ \\
\hline Intercept & & 43.48 & & & \\
\hline Condition & non-rhyme (1), rhyme $(-1)$ & 1.69 & 0.95 & 1.78 & 0.09 \\
\hline Trial & linear orthogonal & -13.16 & 3.49 & -3.77 & 0.0002 \\
\hline Condition * Trial & & -1.05 & 3.47 & -0.30 & 0.76 \\
\hline
\end{tabular}

indicated no significant difference in looking times for rhyming and non-rhyming songs $(t=1.78, \beta=1.69, p=0.09$; effect of Condition in Table 2; see also Fig. 2). Looking times decreased over the course of the experiment $(t=-3.77, \beta=-13.16, p=0.0002$; effect of Trial in Table 2). There was no significant interaction between trial number and condition $(p=0.76)$.

The paired $t$-test on the difference in looking time between rhyming and non-rhyming songs was also not significant $\left(M_{\text {non- }}\right.$ rhyming $\left.=7.22 \mathrm{~s}, S D_{\text {non-rhyming }}=3.71, M_{\text {rhyming }}=6.08 \mathrm{~s}, S D_{\text {rhyming }}=3.05, t(34)=1.661, p=0.11,95 \% C I[-0.25,2.53], r=0.30\right)$. Eighteen of the 35 participants had a preference for the non-rhyming songs. The effect size was small (Cohen's $d_{\mathrm{z}}=0.28$, Hedges' $g_{\text {av }}=0.33$ ).

For sake of completeness we inspected the two training trials of the experiment and found that only 18 of the 35 infants actually contributed a trial for both conditions, that is, they listened long enough to both training trials to reach the end of the second phrase of the song. For this subset of the sample, we found a numeric preference for rhyming over non-rhyming songs $\left(M_{\text {non-rhyming }}=\right.$ $11.69 \mathrm{~s}, S D_{\text {non-rhyming }}=7.59, M_{\text {rhyming }}=13.05 \mathrm{~s}, S D_{\text {rhyming }}=7.17$ ). We did not confirm this difference statistically, due to the relatively small number of trials, items and participants.

\section{Discussion}

The current study investigated whether 9-month-old infants are already able to spontaneously process the phrase-final rhyme in songs. Infants overall listened longer to non-rhyming songs compared to rhyming songs despite the fact that around half of the infants showed a preference for rhyming songs. This suggests that infants are able to process the rhyming pattern at phrase endings in songs. Our results bear the potential that songs in general and rhyming words at phrase ends in songs in particular are an accessible source of phonological structure learning for infants. Early rhyme sensitivity and individual differences there in can thus be studied with relatively simple paradigms and ecologically valid stimuli. Our design can also function as an example for future studies to explore the association between language play and later literacy development. However, since the effect of interest did not reach standard levels of statistical significance, future replications are necessary before firm conclusions can be drawn. Potential directions for methodological improvements will be discussed further below.

The evidence obtained in this study adds to previous research on infants' processing of rhyme in spoken single words (Jusczyk et al., 1999 and R.A. Hayes et al., 2000, 2009). So far, there has only been evidence for infants' spontaneous processing of phonological overlap at word onsets, but not offsets (Jusczyk et al., 1999) and for rhyme processing after extensive training (2009, Hayes et al., 2000). The current study extends these previous results, suggesting that 9-month-old infants can spontaneously process phonological overlap at word offsets and do not require any training to do so. It may be important that the rhyming information is transmitted in a natural and accessible stimulus, which a song provides.

The stimuli in the present study had two crucial features. First, our rhyming stimuli were embedded in prototypical children's song melodies. Previous research has shown that language processing in infants as well as adults benefits from the tight coupling of linguistic and musical information in songs (Bebout \& Belke, 2017; Lebedeva \& Kuhl, 2010; Thiessen \& Saffran, 2009). Second, rhymes were placed at phrase boundaries. The phrase boundary position in speech is of particular salience to infants (Johnson et al., 2014) and 6-month-old infants already are sensitive to phrase boundaries in songs (Hahn et al., in prep). Future studies are needed to disentangle how sung versus spoken material and rhyming phrases versus isolated words each contribute separately to infants' rhyme processing.

A preference for phonological overlap has been reported for adults, when listening to rhyming versus non-rhyming poems (Obermeier et al., 2013), and for 9-month-old infants, who displayed a preference for phonological overlap at word onsets but not at rhyme position (Jusczyk et al., 1999). With respect to the linguistic input that infants are exposed to, rhymes are highly frequent in the lyrics of songs and nursery rhymes (Burling, 1966; Rubin, 1995). The results from the song exposure questionnaire, as filled out by parents of infants participating in this study, suggested that our 9-month-old Dutch participants had vast experience with rhymes in their input, in particular in songs. As we noted earlier, a preference in either direction (rhyming/non-rhyming songs) would indicate infants' spontaneous processing of rhymes in songs. Because listeners tend to prefer phonological overlap, and infants often display a preference for the linguistic structures that surround them (e.g. Höhle, Bijeljac-Babic, Herold, Weissenborn, \& Nazzi, 2009; Segal \& Kishon-Rabin, 2012; Swingley, 2005), a preference for the rhyming songs could have been expected. Contrary to this expectation, infants in the present experiment overall displayed a preference for the less common non-rhyming songs. As rhymes are particularly frequent in songs, the preference for the non-rhyming pattern may be specific to the sung register, and, for example, not generalize to spoken single words (Jusczyk et al., 1999, experiment 1). This stimulus specific interpretation of the preference direction has been suggested earlier (Bergmann \& Cristia, 2016). Yet, given the fact that half of the sample displayed a preference for rhyming songs, infant age and cognitive/linguistic maturation may play a role as well (Hunter \& Ames, 1988). These individual 
differences in early rhyme sensitivity bear great potential for further research, for example exploring the amount and quality of rhyming input and its relation to future linguistic development.

Two approaches were deployed to analyze the data for this study: $t$-tests, which are traditionally used to analyze infant lookingtime data, and mixed effects models, which have been making their way into the analysis of infant behavioral data (Consortium, 2017; Tsuji, Fikkert, Yamane, \& Mazuka, 2016). The mixed-effect model may have been more sensitive to the effect of rhyme on infants' looking behavior, as it simultaneously accounts for variance introduced by individual participants as well as individual songs. Moreover, it better fits the data structure of the current study, with varying number of trials per participant and condition. The $t$-test, in contrast, aggregates over songs and trials. Accounting for nuisance variance in the data may be generally important in infant looking time experiments, as the effect sizes in such experiments tend to be small (Bergmann et al., 2018; but see again: Csibra et al., 2016). In the present study, the observed effect size $\left(d_{z}=0.28\right)$ was substantially smaller than the anticipated effect size $\left(d_{z}=0.5\right)$. Moreover, it is conceivable that the song stimuli elicited more variance in the responses of the infants the typically used spoken stimuli. As a result, a statistical method that accounts for all these sources of variance would be the best suited to detect such subtle effects.

Future studies could improve on the methodology employed in this study in several ways: First, a considerable amount of trials had to be excluded from the analysis. The first rhyme necessarily only occurred at the end of the second phrase, requiring infants to listen for an average of six seconds before data collection for a given trial could start. On $44 \%$ of trials, infants did not listen long enough to reach this time point in the trial. Using shorter melodic phrases could help avoid this problem. Second, the stimuli were rather complex: The Nonsense-Dutch used for the song lyrics could have hampered infant' processing of the phonological content. Future studies could use the infants' natural native language for the verses and Nonsense-Dutch for the rhyme words only. This way, stimulus creation would remain relatively simple while the lyrics in general would possibly be more accessible for the infants. Finally, a relatively large set of unknown melodies was used for the stimuli, possibly tiring out the infants. Taken together, a simpler approach using a smaller number of songs that consist of shorter melodic phrases and carry natural native language lyrics could be a promising road for future investigations. Other studies using the Headturn Preference Procedure have successfully shown that infants process songs, using song stimuli that have shorter phrases, and with melodies and lyrics that are repeated in several trials of the experiment (Corbeil, Trehub, \& Peretz, 2013; Lebedeva \& Kuhl, 2010; Thiessen \& Saffran, 2009).

Children's songs and nursery rhymes have a clear and repetitive structure. Young infants might benefit from this structure when detecting complex phonological patterns. In this study, infants detected rhymes at phrase endings, a phonological pattern that they do not seem to detect when presented within word lists (Jusczyk et al., 1999) unless they receive explicit training (Hayes et al., 2000, 2009). Detecting phonological patterns such as rhymes is of great importance to children over the course of linguistic development. Being aware of the rhyme relationship between words has been associated with various linguistic abilities: rhythmic awareness (Wood, 2006), articulation (Mann \& Foy, 2007), phonological perception (Foy \& Mann, 2001) and acquisition of literacy in general (Bryant, Maclean, \& Bradley, 1990; Goswami et al., 2002; Wood \& Terrell, 1998). Children's songs and nursery rhymes might be the earliest contexts in which infants encounter rhymes in their linguistic input. A small number of studies has even shown that early knowledge of nursery rhymes is directly linked to later success in reading and spelling (Bryant, Bradley, Maclean, \& Crossland, 1989; MacLean, Bryant, \& Bradley, 1987).

Here we explored infants' ability to extract phonological patterns from songs. Infants are exposed to children's songs on a daily basis. Potentially, the songs' inherent coupling of melody and lyrics makes them not only an attractive social stimulus to infants, but also a tool for language learning (Thiessen \& Saffran, 2009). In this study, infants overall listened longer to the songs that did not contain a rhyme, suggesting that infants are sensitive to phonological overlap at phrase boundary position in sung input. These results warrant more research to further our understanding of how rhyming songs and other forms of language play support spontaneous language processing abilities in infants.

\section{Funding}

This research did not receive any specific grant from funding agencies in the public, commercial, or not-for-profit sectors.

\section{Additional information}

The song stimuli can be downloaded from: https://osf.io/gnadw/?view_only=fc4ee7caa798455cbda463448061206f. The Supplemental materials contain the lyrics of the song stimuli, English translation of the Dutch parent questionnaire and more detail on some parts of the method.

\section{Competing financial interests}

The authors declare no competing financial interests.

\section{Acknowledgements}

The authors would like to thank Ilona van der Linden for her support in creating the stimuli, Annelies van Wijngaarden for lending us her beautiful voice, Esther Kroese, Renske van der Cruijsen and Francie Manhardt for testing the infants and coding the videos. Furthermore, we would like to thank the First Language Acquisition Group at Radboud University, Nijmegen, NL, Charon 
Translations, Nijmegen, NL and two anonymous reviewers for their helpful feedback.

\section{Appendix A. Supplementary data}

Supplementary material related to this article can be found, in the online version, at doi:https://doi.org/10.1016/j.infbeh.2018. 07.002 .

\section{References}

Bebout, J., \& Belke, E. (2017). Language play facilitates language learning: Optimizing the input for gender-like category induction. Cognitive Research: Principles and Implications, 2(1), 11. https://doi.org/10.1186/s41235-016-0038-z.

Bergeson, T. R., \& Trehub, S. E. (2002). Absolute pitch and tempo in mothers' songs to infants. Psychological Science, 13(1), 72-75. Retrieved from http://www.ncbi. nlm.nih.gov/pubmed/11892783.

Bergmann, C., \& Cristia, A. (2016). Development of infants' segmentation of words from native speech: A meta-analytic approach. Developmental Science, 19(6), 901-917. https://doi.org/10.1111/desc.12341.

Bergmann, C., Tsuji, S., Piccinini, P. E., Lewis, M. L., Braginsky, M., Frank, M. C., et al. (2018). Promoting replicability in developmental research through meta-analyses: Insights from language acquisition research. OSF Preprintshttps://doi.org/10.17605/OSF.IO/3UBNC.

Boersma, P., \& Weenink, D. (2014). Praat: Doing phonetics by computer. Retrieved from:www.praat.org.

Braze, D., McRoberts, G., \& Mc Donough, C. (2011). Early pre-cursors of reading-relevant phonological skills. In S. Brady, D. Braze, \& C. A. Fowler (Eds.). Explaining individual differences in reading: Theory and evidence (pp. 23-44). Psychology Press.

Bryant, P., Bradley, L., Maclean, M., \& Crossland, J. (1989). Nursery rhymes, phonological skills and reading. Journal of Child Language, 16(2), 407. https://doi.org/10. 1017/S0305000900010485.

Bryant, P., Maclean, M., \& Bradley, L. (1990). Rhyme, language, and children's reading. Applied Cognitive Psychology, 11(1990), $237-252$.

Burling, R. (1966). The metrics of children's verse: A cross-linguistic study. American Anthropologist, 68, $1418-1441$.

Casteren, M., van, \& Davis, M. H. (2006). Mix, a program for pseudorandomization. Behavior Research Methods, 38(4), 584-589. https://doi.org/10.3758/ BF03193889.

Cohen, J. (1988). Statistical power analysis for the behavioral sciences (2nd ed.). Hillsdale, NJ, USA: Lawrence Erlbaum Associates.

Consortium, T. M. (2017). Quantifying sources of variability in infancy research using the infant-directed speech preference. Advances in Methods and Practices in Psychological Science (Accepted Pending Data Collection). https://doi.org/10.17605/OSF.IO/S98AB.

Cook, G. (1997). Language play, language learning. ELT Journal, 51(July), 224-231.

Corbeil, M., Trehub, S. E., \& Peretz, I. (2013). Speech vs. singing: Infants choose happier sounds. Frontiers in Psychology, 4(June), 372. https://doi.org/10.3389/fpsyg. 2013.00372.

Costa-Giomi, E. (2014). Mode of Presentation Affects Infants' Preferential Attention to Singing and Speech. Music Perception, 32(2), 160-169. Retrieved from: http:// www.jstor.org/stable/10.1525/mp.2014.32.2.160.

Csibra, G., Hernik, M., Mascaro, O., Tatone, D., \& Lengyel, M. (2016). Statistical treatment of looking-time data. Developmental Psychology, 52(4), 521-536.

De Cara, B., \& Goswami, U. (2002). Similarity relations among spoken words: The special status of rimes in English. Behavior Research Methods, Instruments, \& Computers: A Journal of the Psychonomic Society, Inc, 34(3), 416-423. https://doi.org/10.3758/BF03195470.

Delavenne, A., Gratier, M., \& Devouche, E. (2013). Expressive timing in infant-directed singing between 3 and 6 months. Infant Behavior \& Development, 36(1), 1-13. https://doi.org/10.1016/j.infbeh.2012.10.004.

Delle Luche, C., Durrant, S., Floccia, C., \& Plunkett, K. (2014). Implicit meaning in 18-month-old toddlers. Developmental Science, 17(6), 948-955. https://doi.org/10. $1111 /$ desc. 12164.

Fabb, N. (1999). Verse constituency and the locality of alliteration. Lingua, 108, 223-245.

Falk, S., \& Kello, C. T. (2017). Hierarchical organization in the temporal structure of infant-direct speech and song. Cognition, 163, 80-86. https://doi.org/10.1016/j. cognition.2017.02.017.

Faul, F., Erdfelder, E., Lang, A.-G., \& Buchner, A. (2007). G*Power 3: A flexible statistical power analysis program for the social, behavioral, and biomedical sciences. Behavior Research Methods, 39(2), 175-191. Retrieved from: http://www.ncbi.nlm.nih.gov/pubmed/17695343.

Floccia, C., Nazzi, T., Delle Luche, C., Poltrock, S., \& Goslin, J. (2014). English-learning one- to two-year-olds do not show a consonant bias in word learning. Journal of Child Language, 41(5), 1085-1114. https://doi.org/10.1017/S0305000913000287.

Foy, J. G., \& Mann, V. (2001). Does strength of phonological representations predict phonological awareness in preschool children? Applied Psycholinguistics, 22(3), 301-325. https://doi.org/10.1017/S0142716401003022.

Goswami, U. (2002). In the beginning was the rhyme? A reflection on Hulme, Hatcher, Nation, Brown, Adams, and Stuart (2002). Journal of Experimental Child Psychology, 82(1), 47-57. https://doi.org/10.1006/jecp.2002.2673.

Hahn, L., Benders, T., Snijders, T. M., \& Fikkert, P. (in prep.). Infants' recognition of phrase boundaries in song and speech. Manuscript in Preparation.

Hayes, D. S. (2001). Young children's phonological sensitivity after exposure to a rhyming or nonrhyming story. The Journal of Genetic Psychology, 162(3), 253-259. https://doi.org/10.1080/00221320109597482.

Hayes, R. A., Slater, A., \& Brown, E. (2000). Infants' ability to categorise on the basis of rhyme. Cognitive Development, 15(2000), $405-419$.

Hayes, R. A., Slater, A. M., \& Longmore, C. A. (2009). Rhyming abilities in 9-month-olds: The role of the vowel and coda explored. Cognitive Development, 24(2), 106-112. https://doi.org/10.1016/j.cogdev.2008.11.002.

Hedges, L. V., \& Olkin, I. (1985). In A. Press (Ed.). Statistical methods for meta-analysis Orlande, USA.

Höhle, B., Bijeljac-Babic, R., Herold, B., Weissenborn, J., \& Nazzi, T. (2009). Language specific prosodic preferences during the first half year of life: Evidence from German and French infants. Infant Behavior \& Development, 32(3), 262-274. https://doi.org/10.1016/j.infbeh.2009.03.004.

Hunter, M. A., \& Ames, E. W. (1988). A multifactor model of infant preferences for novel and familiar stimuli. Advances in Infancy Research, 5, 69-95.

International Phonetic Association (1999). Handbook of the international phonetic association: A guide to the use of the international phonetic alphabet. Cambridge University Press.

Johnson, E. K., Seidl, A., \& Tyler, M. D. (2014). The edge factor in early word segmentation: Utterance-level prosody enables word form extraction by 6-month-olds. PloS One, 9(1), e83546. https://doi.org/10.1371/journal.pone.0083546.

Jusczyk, P. W., Goodman, M., \& Baumann, A. (1999). Nine-month-olds' attention to sound similarities in syllables. Journal of Memory and Language, 82, 62-82. Retrieved from http://www.sciencedirect.com/science/article/pii/S0749596X98926055.

Kemler Nelson, D. G., Jusczyk, P. W., \& Mandel, D. (1995). The head-turn preference procedure for testing auditory perception. Infant Behavior \& Development, 16, 111-116. Retrieved from: http://www.sciencedirect.com/science/article/pii/0163638395900128.

Kuznetsova, A., Brockhoff, P., \& Christensen, R. (2016). lmerTest: Tests in linear mixed effects models. Retrieved from:R Package Versionhttps://cran.r-project.org/ package $=$ lmerTest.

Lakens, D. (2013). Calculating and reporting effect sizes to facilitate cumulative science: A practical primer for t-tests and ANOVAs. Frontiers in Psychology, 4, 1-12. https://doi.org/10.3389/fpsyg.2013.00863.

Lebedeva, G. C., \& Kuhl, P. K. (2010). Sing that tune: Infants' perception of melody and lyrics and the facilitation of phonetic recognition in songs. Infant Behavior \& Development, 33(4), 419-430. https://doi.org/10.1016/j.infbeh.2010.04.006. 
Longhi, E. (2009). 'Songese': Maternal structuring of musical interaction with infants. Psychology of Music, 37(2), 195-213. https://doi.org/10.1177/ 0305735608097042.

MacLean, M., Bryant, P., \& Bradley, L. (1987). Rhymes, nursery rhymes, and reading in early childhood. Merrill-Palmer Quarterly, 33(3), 255-281. Retrieved from: http://www.jstor.org/stable/10.2307/23086536.

Mann, V. A., \& Foy, J. G. (2007). Speech development patterns and phonological awareness in preschool children. Annals of Dyslexia, 57(1), 51-74. https://doi.org/10. $1007 /$ s11881-007-0002-1.

Meints, K., \& Woodford, A. (2008). Lincoln Infant Lab Package 1.0: A new programme package for IPL, preferential listening, habituation, and eye-tracking. Retrieved from:1-44. http://scholar.google.com/scholar?hl = en\&btn $\mathrm{G}=$ Search\&q $=$ intitle:Lincoln + Infant + Lab + Package $+1+.+0+:+\mathrm{A}+$ new + programme + package + for + IPL,++ Preferential + Listening,++ Habituation\#1.

Nakata, T., \& Trehub, S. E. (2011). Expressive timing and dynamics in infant-directed and non-infant-directed singing. Psychomusicology: Music, Mind and Brain, 21(1-2), 45-53. https://doi.org/10.1037/h0094003.

Obermeier, C., Menninghaus, W., von Koppenfels, M., Raettig, T., Schmidt-Kassow, M., Otterbein, S., et al. (2013). Aesthetic and emotional effects of meter and rhyme in poetry. Frontiers in Psychology, 4(January), 10. https://doi.org/10.3389/fpsyg.2013.00010.

Quené, H., \& van den Bergh, H. (2004). On multi-level modeling of data from repeated measures designs: A tutorial. Speech Communication, 43(1-2), 103-121. https:// doi.org/10.1016/j.specom.2004.02.004.

R Development Core Team (2012). R: A language and environment for statistical computing. ISBN 3-900051-07-0 R Foundation for Statistical Computinghttps://doi.org/ 10.1007/978-3-540-74686-7. Vienna, Austria http://www.R-project.org/.

Read, K. (2014). Clues cue the smooze: Rhyme, pausing, and prediction help children learn new words from storybooks. Frontiers in Psychology, 5(February), 1-10. https://doi.org/10.3389/fpsyg.2014.00149.

Rubin, D. C. (1995). Memory in oral traditions: The cognitive psychology of epic, ballads, and counting-out rhymes. New York, NY: Oxford University Press.

Segal, O., \& Kishon-Rabin, L. (2012). Evidence for language-specific influence on the preference of stress patterns in infants learning an iambic language (Hebrew). Journal of Speech Language and Hearing Research, 55(5), 1329. https://doi.org/10.1044/1092-4388(2012/11-0087).

Shanahan, D., \& Huron, D. (2011). Interval size and phrase position: A comparison between German and Chinese folksongs. Empirical Musicology Review, 6(4), $187-197$.

Sheingold, K., \& Foundas, A. (1978). Rhymes for some reasons: Effect of rhyme on children's memory for detail and sequence in simple narratives. Psychological Reports, 43, 1231-1234. https://doi.org/10.2466/pr0.1978.43.3f.1231 Retrieved from:.

Stallworthy, J. (1996). Versification. In M. Ferguson, M. J. Salter, \& J. Stallworthy (Eds.). The norton anthropology of poetry(4th ed.). W W Norton \& Company Incorporated.

Swingley, D. (2005). 11 month olds' knowledge of how familiar words sound. Developmental Science, 5, 432-443. https://doi.org/10.1111/j.1467-7687.2005.00432.x/ full Retrieved from.

Swingley, D. (2009). Onsets and codas in 1.5-year-olds' word recognition. Journal of Memory and Language, 60(2), 252. https://doi.org/10.1016/j.jml.2008.11.003.

Swingley, D., Pinto, J. P., \& Fernald, A. (1999). Continuous processing in word recognition at 24 months. Cognition, 71(2), 73-108. Retrieved from http://www.ncbi. nlm.nih.gov/pubmed/10444905.

Thiessen, E. D., \& Saffran, J. R. (2009). How the melody facilitates the message and vice versa in infant learning and memory. Annals of the New York Academy of Sciences, 1169, 225-233. https://doi.org/10.1111/j.1749-6632.2009.04547.x.

Trehub, S. E., \& Nakata, T. (2002). Emotion and music in infancy. Musicae Scientiae, 5(37), https://doi.org/10.1177/10298649020050S103.

Trehub, S. E., Unyk, A. M., Kamenetsky, S. B., Hill, D. S., Trainor, L. J., Henderson, J. L., et al. (1997). Mothers' and fathers' singing to infants. Developmental Psychology, 33(3), 500-507.

Tsuji, S., Fikkert, P., Yamane, N., \& Mazuka, R. (2016). Language-general biases and language-specific experience contribute to phonological detail in toddlers' word representations. Developmental Psychology, 52(3), 379-390. https://doi.org/10.1037/dev0000093.

Werker, J. F., Polka, L., \& Pegg, J. (1997). The conditioned head turn procedure as a method for testing infant speech perception. Early Development \& Parenting, 6(September), 171-178. Retrieved from: http://infantstudies.psych.ubc.ca/uploads/forms/1252960095WerkerPolkaPegg_1997.pdf.

Wood, C. (2006). Metrical stress sensitivity in young children and its relationship to phonological awareness and reading. Journal of Research in Reading, 29(3), 270-287. https://doi.org/10.1111/j.1467-9817.2006.00308.x.

Wood, C., \& Terrell, C. (1998). Preschool phonological awareness and subsequent literacy development. Educational Psychology, 18(March), 253-274. https://doi.org/ 10.1080/0144341980180301.

Yoshida, K. A., Fennell, C. T., Swingley, D., \& Werker, J. F. (2009). Fourteen-month-old infants learn similar-sounding words. Developmental Science, 12(3), 412-418. https://doi.org/10.1111/j.1467-7687.2008.00789.x. 